\title{
Blending Online Asynchronous and Synchronous Learning
}

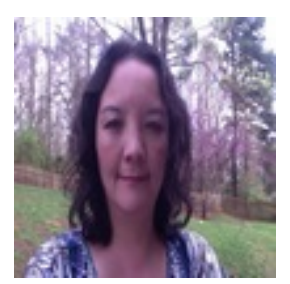

Lisa C. Yamagata-Lynch

University of Tennessee, USA

\section{Abstract}

In this article I will share a qualitative self-study about a 15-week blended $100 \%$ online graduate level course facilitated through synchronous meetings on Blackboard Collaborate and asynchronous discussions on Blackboard. I taught the course at the University of Tennessee (UT) during the spring 2012 semester and the course topic was online learning environments. The primary research question of this study was: How can the designer/instructor optimize learning experiences for students who are studying about online learning environments in a blended online course relying on both synchronous and asynchronous technologies? I relied on student reflections of course activities during the beginning, middle, and the end of the semester as the primary data source to obtain their insights regarding course experiences. Through the experiences involved in designing and teaching the course and engaging in this study I found that there is room in the instructional technology research community to address strategies for facilitating online synchronous learning that complement asynchronous learning. Synchronous online whole class meetings and well-structured small group meetings can help students feel a stronger sense of connection to their peers and instructor and stay engaged with course activities. In order to provide meaningful learning spaces in synchronous learning environments, the instructor/designer needs to balance the tension between embracing the flexibility that the online space affords to users and designing deliberate structures that will help them take advantage of the flexible space.

Keywords: Online learning environments; synchronous learning; asynchronous learning; student reflections 
The purpose of this study was to explore how synchronous online learning can complement asynchronous learning in higher education settings. I will engage in this discussion by introducing a study about a 15-week online graduate level course that I taught in spring 2012 at the University of Tennessee (UT). The discussion of the study will take place within a self-study context where I as the instructor, designer, and researcher engaged in the data collection, analysis, and reporting of the study. The course in which this study took place was about online learning environments.

As a self-study, this work is concerned with making private privileged teaching knowledge public through rigorous and systematic qualitative research methods (Loughran, 2007). In this type of study, the goal of the investigation is to uncover knowledge about practice while recognizing how the self can contribute to scholarly works about teaching and address personal beliefs while acting on them (Hamilton \& Pinnegar, 2000; Hamilton, Smith, \& Worthington, 2008; Loughran, 2005). While engaging in this investigation, I relied on observations shared by LaBoskey (2004) about the five elements of self-study methodologies that recommends that the study (a) is self-initiated and focused, (b) is improvement aimed, (c) is interactive, (d) relies on multiple primarily qualitative methods, and (e) uses exemplar-based validation.

Findings from this type of work generates moderatum generalizations that are moderate in scope and are open to change, but are testable for future confirmation or refutation when new evidence is uncovered (Payne \& Williams, 2005). As an instructional designer the moderatum generalizations that I am able to offer to the scholarly community are design lessons related to designing, developing, and implementing online courses and how those lessons apply to future course and program designs. With that being said, I approach design as an ill-defined problem solving activity in messy-real world situations (J onassen, 2011; Rowland, 1993). As a designer, I framed the reporting of this study following the traditions of design case studies where the goal is to build design knowledge based on precedents (Howard, Boling, Rowland, \& Smith, 2012). While this work is not a design case in itself, based on evidence from teaching experiences and student reflections much of the data analysis and reporting efforts were put into sharing design experiences from a reflective practitioner perspective (Schön, 1987).

I will begin this article with background information about myself as the designer/instructor and the course. While it may seem awkward to begin a research report with this type of autobiographical sketch, in a self-study it is important for the reader to have this information to fully understand the study context to see the privileged data through the perspective of the self. Following the background information, I will introduce literature on current trends in blended online learning and online synchronous and asynchronous learning. Finally, I will present findings and implications for future practice, research, and design of online synchronous learning. 


\section{Designer/ Instructor and Course Background}

I have been working in higher education institutions as a faculty of instructional technology since 2001. I began my career primarily teaching face-to-face courses, but gradually my teaching modality shifted from face-to-face to blended face-to-face/ online, and to fully online. Eventually, I made career choices where I became the program coordinator of a $100 \%$ online instructional technology master's program at UT. The course that I will be discussing in this article is one of the first courses I taught at UT.

Prior to my arrival to UT, faculty had made a curricular decision that the course I will discuss in this article was to be delivered $100 \%$ online. I also learned that within my department most online delivery was synchronous and not asynchronous. This was new to me because in the past all of my online courses relied on asynchronous communications using learning management systems such as Blackboard and Moodle.

I first made the decision regarding the course design to rely on university supported online instructional delivery technologies to ensure that students would have access to full time support from the university information technology services office. These tools were bundled as part of the learning management system and included discussion boards for asynchronous activities on Blackboard and a synchronous meeting platform on Blackboard Collaborate. I chose to design the class as a blended online course with 50\% asynchronous discussions and 50\% synchronous online meetings. During the 15 weeks of the course, weekly activities typically started with students reading assigned materials. Then they participated in asynchronous discussions about the readings and other related topics and/ or activities. When the course met synchronously they engaged in whole class and team synchronous activities related to the weekly topic.

\section{Research Goals}

This was the first time that I designed and implemented a 100\% online course equally relying on both synchronous and asynchronous technologies, and I was struck by a very simple question: How can the designer/instructor optimize learning experiences for students who are studying about online learning environments in a blended online course relying on both synchronous and asynchronous technologies? It is apparent that this question stemmed from a personal level and because of that this article is based on a self-study, but I have taken measures to present this study in a rigorous manner.

The availability of video and text exchanges on personal computers, smart phones, and social media in the United States has resulted in many American adults relying on online videos as an everyday source of information (Percell, 2013). In the business world virtual teams relying on document sharing and synchronous meeting technologies has risen (Anderson, McEwan, Bal, \& Carletta, 2007). Therefore, a discussion of pedagogically sound blended online course design that goes beyond the shortfalls of 
text-based chat and explores the advantages of video conferencing synchronous communications is a timely topic.

Many research studies in the field of education introduce asynchronous discussions as a tool to instill active student participation. As I prepared for developing my course, relying on ideas from authors such as Palloff and Pratt (2007), Gayol (2010), and Garrison and Cleveland-Innes (2005), it became clear that most research on online learning environments has focused on asynchronous communications. In contrast, synchronous chat communications are often introduced as an optional means to engage students in discussions. However, there is often a caveat that synchronous chats are likely to be ineffective due to the chaotic nature of rapid exchanges (Hrastinski, 2010; J ohnson, 2006; Petty \& Farinde, 2013).

\section{Relevant Discussions to Synchronous Online Learning}

In this section I will introduce several issues related to online synchronous and asynchronous learning. I will start by introducing the recent discussions that point to the newly heightened interest in blended learning within higher education for effectively and efficiently providing optimal learning experiences to students. Then I will introduce literature on synchronous online learning and asynchronous participatory online learning.

\section{Heightened Interest among Higher Education Administrators in Blended Learning}

Recently online education has become a topic of discussion in the mainstream news and research literature related to higher education. Many university presidents are showing interest in online learning as a viable mode of instruction (Young, 2011). Online education is now being touted as a method to make educational opportunities accessible to a wide range of audiences. It has been gaining attention as a vehicle for improving pedagogy, introducing flexibility in student access to instruction, and lowering costs associated with education (Graham, 2006; Taplin, Kerr, \& Brown; 2013). Interests in online education among higher education and corporate professionals have risen to the point that Carnegie Mellon University is now leading the creation of a consortium including other universities and corporate entities for developing standards to promote best practices for online learning (O'neil, 2013).

There are also efforts to better define blended learning; however, in many cases the answer to what is blended learning is "it depends." For example, Graham, Woodfield, and Harrison (2013) introduced a spectrum of course delivery modalities in higher education that situated blended learning within the context of traditional face-to-face delivery and completely online delivery with a caveat that institutions of higher education liberally label course delivery modes as blended as long as they are 
somewhere on the spectrum. Similarly, several authors have pointed out that institutions of higher education may refer to blended learning as a combination of online and face-to-face learning when it involves anywhere from $20 \%$ to $80 \%$ blending of online instruction with traditional face-to-face courses. In many cases, there is no agreed upon percentage of what constitutes a course as blended, and in many institutions there are idiosyncratic definitions of online, distance education, and blended instruction.

Graham (2006) defined blended learning not based on percentages of instructional delivery mode, but on what is being blended. Graham, referred to instructional modalities/ delivery media, methods, and the ratio of online and face-to-face instruction as elements that all take a role in defining blended learning. Blended learning has also been referred to as a catalyst of potential change in institutions of higher education because there is a little bit of old and new mixed together, but it needs a better articulated definition so that higher education institutions can align their strategic goals to be successful at facilitating blended learning (Moskal, Dzinban, Hartmen, 2013). Therefore, blended learning has been found to not only bring flexibility into student learning, but also to help institutions explore efficient use of space and faculty time (Dziuban, Hartman, J uge, Moskal, \& Sorg, 2006).

\section{Synchronous Online Learning}

Much of the current scholarly discussions related to designing online learning environments within instructional technology are focused primarily on asynchronous communications. While looking for books and articles that specifically discussed synchronous pedagogy I found Finkelstein (2006) in recent works, and older publications related to interactive video conferencing such as Knox (1997), Carville and Mitchell (2000), and Fetterman (1996). The older literature tended to discuss the effectiveness of video-conferencing compared to face-to-face meetings and the potential of video-conferencing to deliver education to geographically remote learners who do not have access to traditional educational facilities. In many cases, these articles established a discussion for how video-conferencing tools can be a legitimate media for instruction, but did not provide insights on how to engage students in active learning. One article that provided pedagogical insights for both synchronous and asynchronous learning was Bonk and Cummings (1998) where the authors discussed their experiences teaching online and aligned their ideas about teaching online to the American Psychological Association's Learner Centered Psychological Principles.

Within more recent literature related to synchronous communications Asterhan and Schwarz (2010) pointed out that there is little discussion regarding how to effectively support learners in synchronous online learning environments. Asterhan and Schwarz conducted a study regarding online synchronous group discussions and effective moderation that relied on a communication tool that enabled participants to communicate through text and diagramming. Their study included $9^{\text {th }}$ grade students and graduate students. Participants from both groups expected a good moderator to be 
active and keep the live discussions focused to help participants to stay on topic. Participants also reported that they did not necessarily desire the moderator to insert his or her expert opinion regarding the topic during the discussion. Asterhan and Schwarz concluded that the type of dialogue that the instructor facilitated and the degree to which students were engaged in synchronous collaborative discussion affected student-learning outcomes for both the $9^{\text {th }}$ grade students and graduate students. They also concluded that the nature of discussion in asynchronous and synchronous online discussions was qualitatively different. Other studies have found that while engaged in synchronous learning when compared to asynchronous learning participants (a) find a stable means of communication, (b) tend to stay on task, (c) feel a larger sense of participation, and $(\mathrm{d})$ tend to experience better task/course completion rates (Chen \& You, 2007; Mabrito, 2006; Hrastinski, 2010).

In terms of the use of video conferencing in university synchronous instruction Han (2013) examined the effects of instructor video casting on his/her students' sense of connection to the instructor. Han found that in courses that included instructor video casting, compared to courses that did not use video casting, students were able to overcome the sense of being at a distance from the instructor. The use of video casting helped Han's study participants to engage in meaningful interactions with the instructor and peers to minimize what Moore $(1993,2013)$ discussed as transactional distance. According to Moore (1993) transactional distance is a pedagogical concept that learners at a distance from their instructors and peers experience through their interactions with one another and defines the nature of their relationship. Participants may sense more or less transactional distance in an online course depending on the level of shared dialogue, the structures that the instructor puts in place, and the level of autonomy participants experience in a course (Moore, 2013).

\section{Asynchronous Online Participatory Learning}

Studies about asynchronous online learning suggest that students will experience meaningful learning when they are in participatory learning environments (Pratt \& Palloff, 2011). These environments are intentionally designed to help participants develop a sense of community to provide them with opportunities to engage in collaborative discussions. These interactions encourage participants to actively construct new meanings related to the course content (Conrad \& Donaldson, 2011; Lehman \& Conceição, 2011). Asynchronous online participatory learning involves a series of highly complex and ill-defined activities that requires participants to reflect and question their traditional learning practices while developing a new identity as a learner (Palloff \& Pratt, 2011).

The success of community development efforts in an asynchronous text-based learning environment is often associated to how much participants feel present within the shared space. Works such as Garrison, Anderson, and Archer's (2000) study related to the community of inquiry model played a considerable role in bringing attention to the value of presence in online asynchronous learning environments. These works 
heightened interest among researchers and practitioners in how social presence, teaching presence, and cognitive presence affect participants' level of engagement. Garrison and Cleveland-Innes (2005) also found through a multi-case comparison study of asynchronous courses that participant interaction alone does not instill a shared feeling of social presence or engagement in an online course. They found that participants of asynchronous online courses need structures placed by the instructor/designer or participants themselves to help them engage in meaningful learning activities. By understanding presence and its relation to participant engagement in a course from its physical, social, emotional, and psychological aspects designers of online learning environments are able to understand the inherently social nature involved in human learning that needs to be carefully addressed in asynchronous learning environments (Lehman \& Conceição, 2011).

For many adults who attend asynchronous online programs the developmental process involved in understanding and becoming a participatory learner is a completely new experience (Arbaugh, 2004). Most adults need to adjust their role as a learner and the way they understand the role of the instructor. This can be a unique individualized process, but in many cases prior to becoming an effective online participatory learner students need assistance learning how to (a) use technologies involved in managing their online course experiences, (b) navigate course materials, and (c) engage in appropriate communication with other participants (Motteram \& Forrester, 2005). Ultimately, to succeed in online programs, students need time to figure out how to make their online course related activities fit into their lives while managing other obligations for family and work (Muilenburg \& Berge, 2005).

\section{Study Methods}

I engaged in this self-study as the instructor/designer of a course by taking a development research approach (Brown, 1992; The Design-Based Research Collective, 2003). I acted as a participant observer (Glesne, 2011) and took a critical role in the course design and instruction. While engaging in the practice of designing and teaching the course during the fall 2011 and spring 2012 semesters research took a secondary place, and my primary goal was to develop and implement the course. This type of development research can be difficult, but has been identified as necessary when developing and investigating effective collaborative online degree programs (Reeves, Herrington, \& Oliver, 2004; Wang \& Hannafin, 2005).

\section{Completing a Worthwhile Self-Study}

First self-study research has to take place and be reported within a well-grounded context that provides reasons for why the reader ought to be engaged with the topic and trust the author's reflexive findings (Feldman, 2003). In a rigorous qualitative study the topic that is being studied has to be worthwhile (Tracy, 2010). To this end I have (a) 
shared my autographical background related to this self-study for the reader to develop his/her understanding of the investigator as the self, and (b) presented scholarly discussions relevant to this work in terms of online learning and methodological issues.

Second, a high quality self-study requires the researcher to sensitively balance the tension between reporting about him/herself and the research (Freeman, et al., 2007). Through this process the researcher has the opportunity to demonstrate his/her sincerity by addressing biases and self-reflexive findings. This enables the researcher to be transparent about methodological challenges (Tracy, 2010). I engaged in this balancing act throughout the writing of this report by strategically constructing the organization of the report to best represent this balance.

Third, I engaged in data triangulation (Denzin, 1989) by collecting data from multiple sources. For each participant I had access to both primary and secondary data sources. The primary data source for this study was the student reflection papers that were part of the course assignments (see Appendix). I collected these reflections at three different times during the semester. I tested the guiding framework for the reflection paper in a different study (Yamagata-Lynch, Click, \& Smaldino, 2013) where we relied on activity systems analysis (Engeström, 1987) as a tool for engaging students in reflection on activities in an online course that blended synchronous meetings on Second Life and asynchronous discussions on Blackboard. All students enrolled in the course completed this assignment, but for the purpose of this study I had voluntary permission from eight out of a total 13 students to review their reflection papers.

I had access to various secondary data sources such as student assignments, synchronous participation recordings, and asynchronous discussion board postings. I had access to an anonymous student initial course survey that I created asking students to identify past experiences as online learners. I also had access to the end of semester university student course evaluation comments. Finally, as part of my own tenure and promotion process I had a fellow faculty member observe and comment on one week's worth of asynchronous and synchronous course activities.

In terms of data analysis I started by reading and re-reading the student reflections to engage in a thematic analysis (Merriam, 2009). These reflections became the starting point for identifying emerging themes, which then guided me while constructing the narrative presented in the findings. As I prepared the narratives based on themes that emerged I relied on my reflections and secondary data sources to uncover contextual information. 


\section{Findings}

\section{Participant Characteristics}

Among the eight participants in this study, one student was male and the others were female. While none of the participants shared the same professional background, all participants were involved in jobs or areas of research related to adult learning. Most participants were working professionals except for two full time graduate students. The contexts in which participants worked or conducted research included corporate training, higher education, nursing, and teacher professional development.

Through the anonymous initial course survey regarding student online learning experiences most students indicated that my class was not their first online course. Several of them had experiences taking courses that were blended asynchronous and face-to-face, fully asynchronous, or fully synchronous, but they did not have experience in a blended synchronous and asynchronous format. Some students who were taking my course as an elective shared in their reflections that in courses they had taken in the past, synchronous meetings were plagued with technical difficulties and they were not looking forward to the once a week meetings set aside for my class. Others indicated in the anonymous survey that they had expected my class would be a "self-paced," "passive asynchronous course." These students were a little taken aback by the synchronous and participatory collaborative nature of my course after reading the syllabus and weekly course activities expectations.

Some students continued to share this initial apprehension regarding synchronous activities when they wrote their first reflection paper. For example, Tracy shared that she was "more comfortable with the old idea of isolation and online lectures than collaboration and engaged learning... This [course] makes me very anxious" (Reflection Paper 1, January 2012). Samantha echoed this sentiment in her first reflection, and indicated that all of her past experiences with online courses involved self-paced asynchronous activities, and she was initially expecting my course to follow that format.

When sharing reasons for why students chose to enroll in my class in the anonymous survey, most students indicated that in the future they were likely to be involved in designing online courses themselves and they were interested in learning how to best facilitate adult learning online. Even though they had experienced several online courses prior to my class this was the first time where the topic was about facilitating online learning. Therefore, many participants commented that they came into the course slightly anxious about the live weekly meetings, but they were willing to give their best try to become familiar with how to learn and facilitate learning through synchronous online communications. 


\section{Requirements for Successful Blended Synchronous and Asynchronous Online Learning}

\section{Students need to be familiar with synchronous meeting tools.}

The reason why students were apprehensive about the synchronous meetings stemmed from difficulties they had or they heard about from colleagues in other courses related to synchronous meeting technologies. For example, Samantha shared in her first reflection that in one of her past online courses where the content was delivered primarily asynchronously with three synchronous meetings even until the last course meeting there were students who never learned how to use the communication tools appropriately and inevitably during all three sessions there were students who were stuck in the "what I can't hear you" situation. She commented that without technical proficiency shared among all participants, the synchronous platform could become "just a clunky environment" that takes time away from student learning opportunities.

Greg shared in his first reflection paper when discussing how he became familiar with the synchronous learning tools that he realized for an online synchronous course the community extends beyond the instructor and participants. After registering in my class he decided to voluntarily attend a two-hour workshop hosted by the university technology support office on Blackboard Collaborate prior to the first week of class. By learning about the synchronous tools prior to the course meeting he became comfortable with the learning space and felt ready to use it as a classroom and not a place where he would become overwhelmed with the technical aspects.

Yumin also shared how she felt about being prepared for the synchronous meetings in her first reflection paper. She commented that on the first day of class she was initially nervous about the synchronous aspects of the course. However, after the class met for the first time she realized that other course participants were approximately at the same technological proficiency level as she was and this made her much more comfortable to take part in the class.

\section{Ground rules need to be enforced.}

Several students in their reflection papers indicated that through their experiences in my class they had a newfound appreciation for course ground rules. During the first week of class, following suggestions from assigned readings, I introduced to the class a draft of the course ground rules. Based on prior experience, and another week's worth of readings students engaged in asynchronous discussion and synchronous small group discussions to review the ground rules and suggest modifications. During the whole group synchronous discussion in the second week of the course we reached a consensus and finalized the ground rules, with the understanding that whenever necessary any member of the course can suggest modifications for all to review. At this point the ground rules included items in Table 1. For the rest of the semester, these ground rules helped to set both synchronous and asynchronous course participation expectations. 
While reflecting on the value of ground rules of an online course Betty shared in her third reflection paper that

I have developed a deeper respect for course ground rules. In an online learning environment, without the familiar constraints of classroom walls, ground rules are not as easily assumed...Having online ground rules explicitly stated and always available helps to ensure a healthy, safe, and respectable learning environment. (Reflection Paper 3, April 2012)

Table 1

Course Ground Rules

1. Be prepared for synchronous sessions by having access to and properly set up computer equipment and USB headphones/microphone for each session.

2. Be proactive about seeking help from the instructor regarding course issues and OIT for technical troubleshooting.

3. Be open-minded and share my own ideas as well as listen to ideas that others share about themselves and my work even when at times they may be difficult advice.

4. Be able to take the time to think before responding to others.

5. Be responsive and communicative to other participants through email, asynchronous discussion, and synchronous discussions.

6. Be open to comments from other participants, and do not assume that they are negative, instead assume that they are positive and supportive.

7. Be self-disciplined and take charge of managing my own learning by making the time to read, participate, and reflect on course activities.

8. Be honest, respectful, and open while interacting with other participants.

9. Remember that discussion posts for this course are due $7 \mathrm{pm}$ on the due date, and formal assignments are due 11:59pm of the due date.

10. Side discussions during synchronous sessions are welcomed in this course as long as they do not disrupt anyone's work. When participants of the side discussions determine that their conversation would benefit the entire class one of the participants need to raise their hand to make others aware of the side discussion content.

11. Focus Wiki articles to more recent work, preferably from the last 5 to 7 years unless the selected older work is cited frequently by more recent work.

The ground rules helped identify formal rules that students could then interpret as a guide to identify how to behave appropriately in course related activities in both the synchronous and asynchronous platforms. For example based on these ground rules, Kelly shared in her second reflection paper the efforts she put into presenting herself during synchronous meetings as a fully attentive, respectful, and participative student to others. Her efforts included:

...online etiquette rules (e.g., maintaining a presence by marking "checks" when appropriate, or indicating "applause" (or other) when applicable, not interrupting 
speakers, keeping side chats brief and non-distracting); tacit rules of general politesse and professionalism; communication with the instructor directly as concerns/questions arise (Reflection Paper 2, March 2012).

Once the ground rules were set, to a certain extent I as the instructor relied on students to responsibly enact them. However, Samantha pointed out in her reflection paper there could have been reinforcement of the ground rules every now and then during the semester. For example, during the entire semester we had issues with students not following the ground rules and course requirements in the syllabus related to participating in class with a USB headphone and a microphone. Some students chose for themselves that they did not have to follow this requirement. While I did not receive complaints directed to me during private synchronous meetings or through email, in the final reflection paper that was due at the end of the semester several students commented that when other students did not use a USB headphone and microphone during synchronous sessions it made it difficult to communicate with them and challenging to fully engage in group learning activities.

\section{Students need to know where the course is heading.}

Several students commented in their reflections that while participating in an online course it is important for them to gain a sense of structure and where the course is heading. For example, Betty shared in her first reflection: "Before I begin any online course work my initial goal is to ground myself in organization.. I create structure from calendar due dates, task lists, and management of course content" (Reflection Paper 1, January 2012). Students also commented that they needed to spend time at the beginning of the semester to learn how to organize their own course related efforts within the structure of the course provided by the instructor. Betty in her third reflection commented that when she is able to organize her time within the structure of the course she becomes able to fully participate with a sense of stability in both the synchronous and asynchronous platforms. She commented: "I believe the overall nature of stability ensured my participation and engagement with course activities and connections with fellow classmates remained high and fully engaged" (Reflection Paper 3, April 2012).

Kelly, Greg, and Tracy all commented that the sense of direction that they gained from the structure I provided for the course in the syllabus and the way they organized their work to accommodate the structure of the course provided them with reasons to exert their energy into the participation of both synchronous and asynchronous activities. For example, Kelly found the small group breakout synchronous meetings to be very difficult to participate in and Greg found the asynchronous discussions difficult to fit into his busy life juggling school and work. Both students pointed out in their reflection paper that as long as they knew the purpose of each activity in the bigger picture of the course and their personal goals for the course they were able to make themselves 
continue to be interested in activities they felt less comfortable and personally less interested in.

\section{Benefits from Synchronous Online Learning}

Students shared that being part of an online blended synchronous and asynchronous course gave them the opportunity to experience a higher level of participation in a flexible learning environment where they had no time to be a passive non-present student. For example, Greg commented that as a general trend when he is in online courses he often needs to find ways to stay engaged throughout a semester while juggling his busy work life. Through the blended format and seeing how the asynchronous activities built towards the synchronous meetings he was able to continue participating in the asynchronous activities. Additionally, he saw how some of the other students prefer asynchronous communications, unlike him, and while working to comprehensively participate in class Greg discovered that for him to get to know other course participants he needed to listen to them through both synchronous and asynchronous communications. In some cases, the blended online format of the course helped students gain a stronger sense of connection. Jane commented in her second reflection paper that

During the past nine weeks, I have had the opportunity to interact with all participants in online activities. I feel like I have gotten to know each of the class participants at least as well, and probably better, than I would have in a face-to-face class. (Reflection Paper 2, March 2012)

Some of the other flexible features of the course that students commented were beneficial to their learning included the variety of communication styles that the two technologies brought to the class. Through the synchronous communications they were able to engage in spontaneous discussions while through the asynchronous communications they were able to take the time to reflect and prepare a response for discussion topics that were designed for any given week. A final flexible feature that students enjoyed was that they could work in their own space, and did not have to rely on equipment that was not their own when participating in synchronous meetings. J ane commented in her first reflection paper that it was important to her that her learning space was her own and not in a classroom where she did not have the control to optimize the environment for herself.

\section{Areas of Future Development in Synchronous Online Learning}

In my class the area that students experienced the greatest difficulties with were in the synchronous breakout activities. Greg in his third reflection paper pointed out a simple problem where in breakout rooms someone had to speak up at first so the team did not waste time trying to figure out who would start the conversation. In other comments shared by students in the reflection papers it became clear that they needed more 
guidance structuring breakout sessions. As a response to this finding that I discovered during the course, I started to suggest roles for each participant to take during breakout activities and provided a framework for managing the allotted time for live activities.

Kelly commented in her second reflection paper a similar sentiment as Greg and added that she got frustrated when in small groups other participants were not willing to talk, and this was one reason she felt more comfortable and less frustrated with asynchronous discussions. Kelly kept reflecting on this issue in her subsequent reflections to explore how to make synchronous breakout activities less frustrating. In her third reflection paper she commented:

I think it might really help if participants always used the video feature when they talk. I consider myself a very visual person and I think I have trouble staying engaged (and not getting distracted) when the monitor that I am staring at doesn't change at all. ( Reflection Paper 3, spring 2012)

This was a suggestion I received in my peer teaching evaluation from my colleague as well. My teaching evaluator commented that I was losing the opportunity for participants to develop a stronger connection with each other and in the future I ought to require participants to turn their video on while speaking.

On another note about breakout activities, Tracy commented that she ended up with the same group members several times and it was difficult for each small group activity to stay interesting because the group started to lack varied viewpoints. This was my error from ignorance. As the moderator of the synchronous sessions I relied on a function within Blackboard Collaborate for assigning students randomly into breakout rooms when I created the rooms for each session. I did not realize until later in the semester while reading student reflections that this random assignment was not so random. Therefore, while it was late into the semester I started to create peer rotation groups and created a chart of assigned peer activity groups where students were randomly assigned to three different peer groups.

\section{Conclusions}

I started this article by sharing my experience as an instructor, designer, and researcher of online learning environments in higher education settings. I specifically addressed the potential benefits for integrating synchronous learning into asynchronous course activities because I wanted to see how they can be best matched to benefit student experiences (see LaBoskey, 2004-(a) is self-initiated and focused and (b) improvement aimed). I followed the development research approach where as the researcher, designer, instructor I engaged in iterative just-in-time and long-term modifications of 
the design by responding to evidence from course experiences and student data (see LaBoskey, 2004-(c) is interactive). Following the qualitative research traditions I used multiple methods for collecting course and student data to engage in a trustworthy data collection and analysis (see LaBoskey, 2004-(d) relies on multiple primarily qualitative methods, and (e) uses exemplar-based validation). In this section I will address both the implications related to teaching online courses where I introduce design lessons that I discovered as moderatum generalizations. Then I will introduce implications from those design lessons to the greater scholarly discussions about online learning environments.

\section{Implications for Designing Online Learning Environments}

\section{Online Learning Environments Design Lesson 1: Participants come to online courses with varied participatory learning experiences, and need time to find a new identity as an online learner.}

Many participants of this study had varied experiences in past online courses, and to many of them taking a participatory approach was a foreign concept. This necessitated an adjustment phase for taking on the expectations for becoming a participatory online learner much like observations made by Arbaugh (2004). Similar to findings shared by Motteram and Forrester (2005), participants of this study discussed in their reflection papers that following the course ground rules, overall course structure, and becoming proficient with course technologies helped them become effective course participants. They also shared in their papers that they had to juggle personal, work, and course obligations while participating in course related activities much like what was reported in Muilenburg and Berge (2005). Similar to findings shared by Palloff and Pratt (2011) by engaging in a series of complex course related activities and finding new ways to fit them into their personal learning space, study participants discovered a new identity as online participatory learners.

\section{Online Learning Environments Design Lesson 2: Synchronous delivery modes can provide a stronger sense of connection among participants, and a blended online synchronous and asynchronous course can strengthen social presence.}

Participant reflections specifically related to synchronous technologies indicated that they were in alignment with previous studies relying on text-based chat exchanges. For example, participants reported that they found the nature of synchronous and asynchronous communications to be different from one another similar to what Asterhan and Schwarz (2010) found. Participants sensed a stronger connection to other students while engaged in spontaneous conversations during synchronous meetings that they did not experience in the asynchronous discussions. Students also reported that with the synchronous and asynchronous blended online course format they felt they gained a sense of stability, stayed on task, and gained a stronger connection with other participants similar to what was reported by Chen and You (2007) and Hrastinski (2010). In other words, the synchronous meeting platform that enabled live online video and voice communications between the instructor and participants helped participants develop a stronger sense of social presence. While this work alone cannot speak to how 
the synchronous platform affected the physical, social, emotional, and psychological aspects of social presence that Lehman and Conceiçã (2001) identified, this work indicates that there is room for future investigations related to synchronous online learning and its impact on social presence.

\section{Online Learning Environments Design Lesson 3: Participant experiences are greatly affected by the designer/instructor's ability to bring a sense of cohesion and structure in the synchronous learning environments.}

When reflecting on the experiences I gained through designing and teaching the course and the research findings from this study I find that the instructor/ designer's ability to provide participants with appropriate structures within a flexible shared virtual space takes a critical role in the success of synchronous online learning. This is perhaps similar to what Garrison and Cleveland-Innes (2005) reported in their work regarding the need for structure within asynchronous online learning environments to ensure that participants engage in meaningful learning activities. In a synchronous online learning space the instructor/designer needs to carefully reflect and be deliberate about the structures $\mathrm{s} /$ he makes available to participants because in many cases if the same activity were to take place in a face-to-face setting it is not likely that participants would need the same amount of guidance.

\section{Implications for Studying Online Learning Environments}

At the course design level of scholarly discussion, as the number of online courses relying on synchronous technologies rises in the future, the nature of the tension between structure and flexibility may evolve. As a result, scholars need to purposefully engage in research that questions the transitions in this tension because it is likely to have effects on participant perception of transactional distance (Moore, 1993, 2013). This implies that what we know now from past and current research may no longer be the status quo and online learning environment scholars need to be willing to conceptually change their understanding related to synchronous online learning. As future online learners gain the experiences they need to become savvy synchronous learners they may identify the structures themselves that need to be in place. The continual question for the instructor/ designer/researcher then is to identify when and how much structure within a flexible system is appropriate for their participants based on who the participants are, the course schedule, the content, and the affordances of the synchronous communication technologies. For these continued design improvements to occur at the course level, online learning environment scholars need to move beyond solely examining the asynchronous participatory instructional delivery mode, and explore experiences related to synchronous online delivery beyond text-based chat interactions.

At the programmatic level, much of the current discussion related to online learning focuses on introducing blended learning into higher education as an opportunity for making college education accessible, pedagogically innovative, flexible, and economical 
(Graham, 2006; Taplin, Kerr, \& Brown, 2013). This has resulted in a need for defining what qualifies as blended learning, which has not yielded a consensus on the matter (Graham, Woodfield, \& Harrison, 2013). These discussions represent conversations related to how online learning environments can be assimilated into historical practices of brick and mortar higher education institutions. Unfortunately, using the sole perspective of a brick and mortar institution as the primary vantage point for addressing future developments in online learning limits the potential transformation that it can bring to instructor and student experiences within universities.

Based on the experiences I gained through this investigation and the design lessons I uncovered there are three questions that I propose online learning environment scholars need to address in the future. First, scholars need to address: How can higher education institutions provide meaningfully structured learning experiences within flexible online learning spaces, while not being burdened by their historical highly structured brick and mortar infrastructure? Works that address this question will add to the scholarly discussions related to social presence, transactional distance, and blended learning. The second question that scholars need to address is: How can faculty and university support staff work together to transform faculty into designers of online courses and share their experiences in a scholarly manner? Works that address this question will add to the discussions related to developmental research and self-study research. Finally, scholars who engage in investigations related to the above questions need to address: How can both course and program level design lessons that are discovered through developmental research and self-studies be shared as design knowledge based on precedents? Through these types of scholarly work the online research and practitioner community will be able to refer to moderatum generalizations (Payne \& Williams, 2005) about online learning environments while continuing to design, develop, and implement online learning courses, programs, and research. 


\section{References}

Anderson, A. H., McEwan, R., Bal, J ., \& Carletta, J . (2007). Virtual team meetings: An analysis of communication and context. Computers in Human Behavior, 23(5), 2558-2580. doi:10.1016/j.chb.2007.01.001

Arbaugh, J . (2004). Learning to learn online: A study of perceptual changes between multiple online course experiences. The Internet and Higher Education, 7(3), 169- 182. doi:10.1016/j.iheduc.2004.06.001

Asterhan, C. S. C., \& Schwarz, B. B. (2010). Online moderation of synchronous eargumentation. International J ournal of Computer-Supported Collaborative Learning, 5(3), 259-282. doi:10.1007/ s11412-010-9088-2

Brown, A. L. (1992). Design experiments: Theoretical and methodological challenges in creating complex interventions in classroom settings. The J ournal of The Learning Sciences, 2(2), 141-178. doi:10.1207/s15327809j1s0202_2

Carville, S., \& Mitchell, D. R. (2000). “It's a bit like Star Trek': The effectiveness of video conferencing. Innovations in Education \& Training International, 37(1), 4249. doi:10.1080/135580000362070

Chen, W., \&You, M. (2007). The differences between the influences of synchronous and asynchronous modes on collaborative learning project of industrial design. In D. Schuler (Ed.), Online communities and social computing (pp. 275-283). Berlin Heidelberg : Springer. Retrieved from http://link.springer.com/ chapter/ 10.1007/978-3-540-73257-0 31

Conrad, R.-M., \&Donaldson, J . A. (2011). Engaging the onlinelearner: Activities and resources for creative instruction (2nd ed.). San Francisco: J ossey-Bass.

Dziuban, C., Hartman, J ., J udge, F., Moskal, P., \& Steven, S. (2006). Blended learning enters mainstream. In C. J . Bonk \& C. R. Graham (Eds.), The handbook of blended learning: Global perspectives, local designs (pp. 195- 208). San Francisco: Pfeiffer.

Engeström, Y. (1987). Learning by expanding: An activity-theoretical approach to developmental research. Retrieved from http://lchc.ucsd.edu/MCA/Paper/ Engestrom/expanding/toc.htm

Feldman, A. (2003). Validity and quality in self-study. Educational Researcher, 32(3), 26- 28. doi:10.3102/0013189X032003026

Fetterman, D. M. (1996). Videoconferencing on-Line: Enhancing communication over the Internet. Educational Researcher, 25(4), 23- 27. doi:10.2307/ 1176777 
Finkelstein, J . E. (2006). Learning in real time: Synchronous teaching and learning online. J ossey-Bass.

Freeman, M., deMarrais, K., Preissle, J ., Roulston, K., \& Pierre, E. A. S. (2007). Standards of evidence in qualitative research: An incitement to discourse. Educational Researcher, 36(1), 25- 32. doi:10.3102/0013189X06298009

Garrison, D. R., Anderson, T., \&Archer, W. (2000). Critical inquiry in a text-based environment: Computer conferencing in higher education. The Internet and Higher Education, 2(2-3), 87- 105. doi:10.1016/ S1096-7516(00)00016-6

Garrison, D. R., \& Cleveland-Innes, M. (2005). Facilitating cognitive presence in online learning: Interaction Is not enough. American J ournal of Distance Education, 19, 133- 148. doi:10.1207/s15389286ajde1903_2

Glesne, C. (2011). Becoming qualitative researchers: An introduction (4th ed.). Prentice Hall.

Graham, C. R. (2006). Blended learning systems: Definition, current trends, and future directions. In C. J . Bonk \& C. R. Graham (Eds.), The handbook of blended learning: Global perspectives, local designs (pp. 3- 21). San Francisco: Pfeiffer.

Graham, C. R., Woodfield, W., \& Harrison, J . B. (2013). A framework for institutional adoption and implementation of blended learning in higher education. The Internet and Higher Education, 18, 4- 14. doi:10.1016/j.iheduc.2012.09.003

Hamilton, M. L., \& Pinnegar, S. (2000). On the threshold of a new century trustworthiness, integrity, and self-study in teacher education. J ournal of Teacher Education, 51(3), 234- 240. doi:10.1177/0022487100051003012

Hamilton, M. L., Smith, L., \&Worthington, K. (2008). Fitting the methodology with the research: An exploration of narrative, self-study and auto-ethnography. Studying Teacher Education, 4(1), 17-28. doi:10.1080/ 17425960801976321

Han, H. (2013). Do nonverbal emotional cues matter? Effects of video casting in synchronous virtual classrooms. American J ournal of Distance Education, 27(4), 253-264. doi:10.1080/08923647.2013.837718

Howard, C. D., Boling, E., Rowland, G., \&Smith, K. M. (2012). Instructional design cases and why we need them. Educational Technology, 52(3), 34- 39.

Hrastinski, S. (2010). How do e-learners participate in synchronous online discussions? Evolutionary and social psychological perspectives. In N. Kock (Ed.), Evolutionary psychology and information systems research (pp. 119- 147). US : Springer. Retrieved from http:/ / link.springer.com/ chapter/ 10.1007/978-1$\underline{4419-6139-6 \quad 6}$ 
J ohnson, G. M. (2006). Synchronous and asynchronous text-based CMC in educational contexts: A review of recent research. TechTrends, 50(4), 46- 53. doi:10.1007/s11528-006-0046-9

J onassen, D. H. (2011). Learning to solve problems: A handbook for designing problem-solving learning environments. New York: Routledge.

Knox, D. M. (1997). A review of the use of video-conferencing for actuarial education a three-year case study. Distance Education, 18(2), 225- 235. doi:10.1080/0158791970180204

LaBoskey, V. K. (2004). The methodology of self-study and its theoretical underpinnings. In J. J . Loughran, M. L. Hamilton, V. K. LaBoskey, \& T. Russell (Eds.), International handbook of self-study of teaching and teacher education practices (pp. 817- 869). Netherlands : Springer. Retrieved from http:// link.springer.com/ chapter/ 10.1007/978-1-4020-6545-3_21

Loughran, J . (2005). Researching teaching about teaching: Self-study of teacher education practices. Studying Teacher Education, 1(1), 5- 16. doi:10.1080/17425960500039777

Loughran, J . (2007). Researching teacher education practices responding to the challenges, demands, and expectations of self-study. J ournal of Teacher Education, 58(1), 12-20. doi:10.1177/ 0022487106296217

Lehman, R. M., \& Conceição, S. C. O. (2010). Creating a sense of presence in online teaching: How to "be there" for distance learners. San Francisco: J ossey-Bass.

Mabrito, M. (2006). A study of synchronous versus asynchronous collaboration in an online business writing class. American J ournal of Distance Education, 20(2), 93- 107. doi:10.1207/ s15389286ajde2002_4

Merriam, S. B. (2009). Qualitative research: A guide to design and implementation: Revised and expanded from qualitative research and case study applications in education (3rd ed.). San Francisco, California: J ossey-Bass.

Moore, M. G. (1993). Theory of transactional distance. In D. Keagan (Ed.), Theoretical principles of distance education (pp. 22- 29). New York: Routledge. Retrieved from http:// www.uni-oldenburg.de/ zef/cde/support/readings/moore93.pdf

Moore, R. (2003). Reexamining the field experiences of preservice teachers. J ournal of Teacher Education, 54(1), 31-42.

Moskal, P., Dziuban, C., \& Hartman, J . (2013). Blended learning: A dangerous idea? The Internet and Higher Education, 18, 15- 23. doi:10.1016/j.iheduc.2012.12.001 
Motteram, G., \& Forrester, G. (2005). Becoming an online distance learner: What can be learned from students' experiences of induction to distance programmes? Distance Education, 26, 281-298. doi:10.1080/01587910500291330

Muilenburg, L. Y., \& Berge, Z. L. (2005). Student barriers to online learning: A factor analytic study. Distance Education, 26, 29- 48.

doi:10.1080/01587910500081269

O'neil, M. (2013, November 11). New council to develop standards, best practices for online learning. Wired Campus. The Chronicle of Higher Education. Retrieved from http:// chronicle.com/blogs/ wiredcampus/ new-council-to-developstandards-best-practices-for-onlinelearning/48171?cid=wc\&utm source=wc\&utm medium =en

Palloff, R. M., \& Pratt, K. (2007). Building online learning communities: Effective strategies for the virtual classroom (2nd ed.). San Francisco: J ossey-Bass.

Payne, G., \&Williams, M. (2005). Generalization in qualitative research. Sociology, 39(2), 295- 314. doi:10.1177/ 0038038505050540

Percell, K. (2013). Online video | Pew Research Center's Internet \&American Life Project (p. 23). Washington, D.C.: Pew Research Center. Retrieved from http:// www.pewinternet.org/ Reports/2007/Online-Video.aspx

Petty, T., \& Farinde, A. C. (2013). Investigating student engagement in an online mathematics course through windows into teaching and learning. J ournal of Online Learning and Teaching, 9(2), 261-270.

Reeves, T. C., Herrington, J ., \& Oliver, R. (2004). A development research agenda for online collaborative learning. Educational Technology Research and Development, 52(4), 53-65. doi:10.1007/BF02504718

Rowland, G. (1993). Designing and instructional design. Educational Technology Research and Development, 41(1), 79- 91. doi:10.1007/ BF02297094

Schön, D. A. (1987). Educating the reflective practitioner: Toward a new design for teaching and learning in the professions. San Francisco: J ossey-Bass.

Taplin, R. H., Kerr, R., \& Brown, A. M. (2013). Who pays for blended learning? A costbenefit analysis. The Internet and Higher Education, 18, 61- 68. doi:10.1016/j.iheduc.2012.09.002

The Design-Based Research Collective. (2003). Design-based research: An emerging paradigm for educational inquiry. Educational Researcher, 32(1), 5-8. doi:10.3102/0013189X032001005 
Tracy, S. J . (2010). Qualitative quality: Eight "big-tent" criteria for excellent qualitative research. Qualitative Inquiry, 16(10), 837-851. doi:10.1177/ 1077800410383121

Wang, F., \& Hannafin, M. (2005). Design-based research and technology-enhanced learning environments. Educational Technology Research and Development, 53(4), 5- 23. doi:10.1007/BF02504682

Yamagata-Lynch, L. C., Click, A., \& Smaldino, S. E. (2013). Activity systems as a framework for scaffolding participant reflections about distance education in an online instructional technology course. Reflective Practice, 14(4), 536- 555. doi:10.1080/ 14623943.2013.809336

Young, J . R. (2011, August 28). College presidents are bullish on online education but face a skeptical public. The Chronicle of Higher Education. Retrieved from http:// chronicle.com/article/ College-Presidents-Are-Bullish/ 128814/ 


\section{Appendix}

\section{Online Learner Self Reflection Guide}

\section{Last Updated J anuary 11, 2012}

You will keep a reflective log of your own process of becoming an online learner. You need to complete 3 assigned reflections at the beginning, middle, and end of this course. Follow the Reflection Template guided by activity systems analysis when completing this assignment. Use the form, with the triangle imbedded within it, for completing each of your reflections. There are additional open-ended statements related to your personal learning and the course structure to be completed as well.

This reflection focuses on your course related activities and how you see yourself as an online learner. Please use the following graphical model to clarify what to include in your reflections addressing Subject, Tool, Object, Rules, and Community, Division of Labor. Please indicate any specific conflicts between areas of the model when appropriate in your reflections.

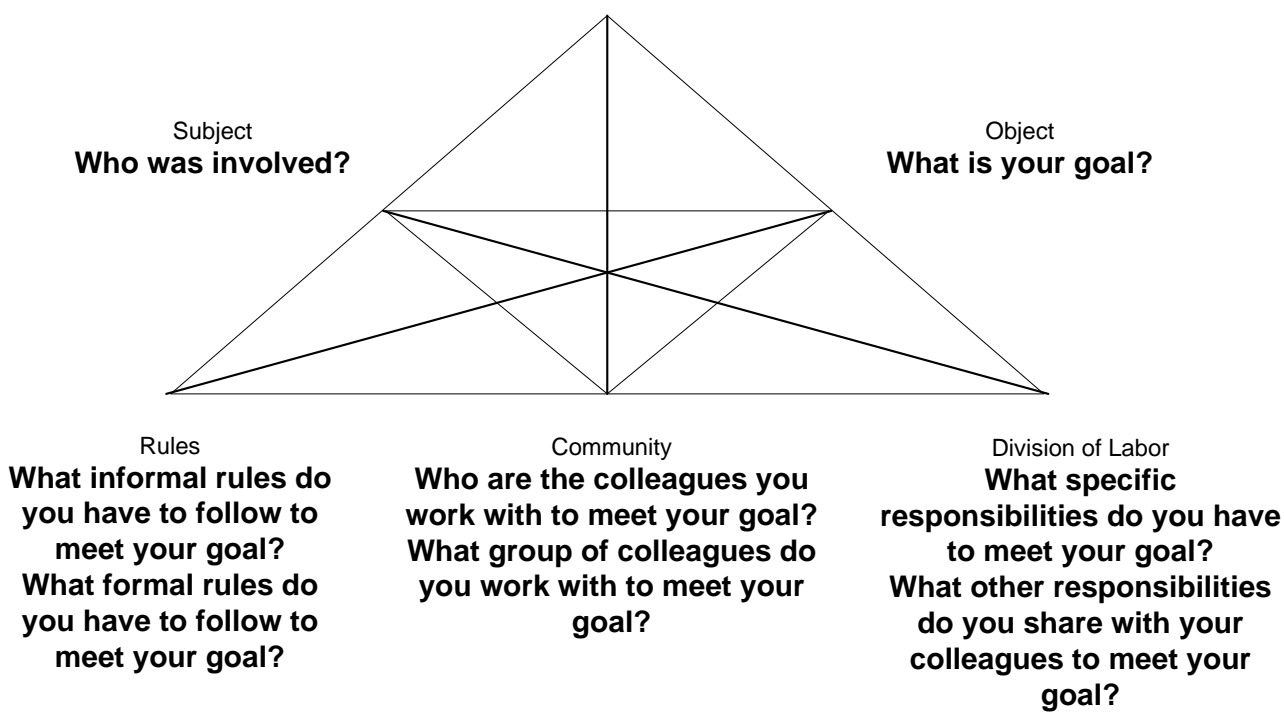

\section{Reflections on Personal Course Activities}

Subject: Participants involved in my recent activities in this course included... 
Tool: Resources related to my course activities were...

Object: My personal goals related to course activities were....

Rules: Formal and informal rules that influenced my course activities were....

Community: Other participants who took a role in my activities were....

Distribution of Labor: The responsibilities that I shared with other participants in these activities were...

The conflicts I found while engaging in course activities were...

The structure of this course helps or impedes my participation in course activities because...

\section{Reflections on How You See Yourself as an Online Learner}

If I were to describe myself as an online learner based on past and current online learning experiences I am...

What I know about myself as an online learner will influence how I design future online courses/ program by...

\section{Athabasca University $\mathbf{1}$}

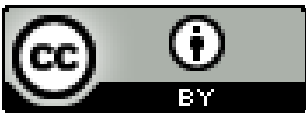

